\title{
Sistema Agroflorestal na Agricultura Familiar
}

\author{
Agroforestry System in Family Agriculture
}

\section{Sistema Agroforestal En Agricultura Familiar}

iD 9 Wanderson Moreira dos Santos

Instituto Federal Goiano

iD 9

Layanny Robert Faria

Instituto Federal Goiano

(iD) Anderson Fabrício Messias Rocha Instituto Federal Goiano

(9) Luís Sérgio Rodrigues Vale Instituto Federal Goiano

(9) Cássio da Silva Kran Instituto Federal Goiano

Resumo: Os sistemas agroflorestais (SAFs) quando implantados e conduzidos sob os princípios da agroecologia e com o manejo adequado possibilitam acelerar os processos de regeneração de sistemas ambientais, como na recuperação de áreas degradadas e na produção de alimentos. Neste sentido, objetivou-se com este projeto restaurar uma área improdutiva com a implantação de um sistema agroflorestal em uma propriedade de agricultura familiar 
no município de Ceres, GO. A metodologia utilizada foi a implantação de um SAF in loco, com participação direta do agricultor e de alunos do IF Goiano - Campus Ceres. No sistema foram introduzidas olerícolas e cultura anual, fruteiras e plantas arbóreas. Após um ano de implantação, o SAF proporcionou incremento no potencial produtivo da área da chácara São Pedro. É uma opção para tornar-se áreas degradadas e/ou não utilizadas/improdutivas em uma área com produção de alimentos, preservação ambiental e promoção do bem estar para as famílias do campo.

Palavras-chave: Agricultura familiar. Agrofloresta. Ecossistema. Segurança alimentar.

Abstract: Agroforestry systems (SAFs) when implemented and conducted under the principles of agroecology and with the proper management make it possible to accelerate the regeneration processes

2

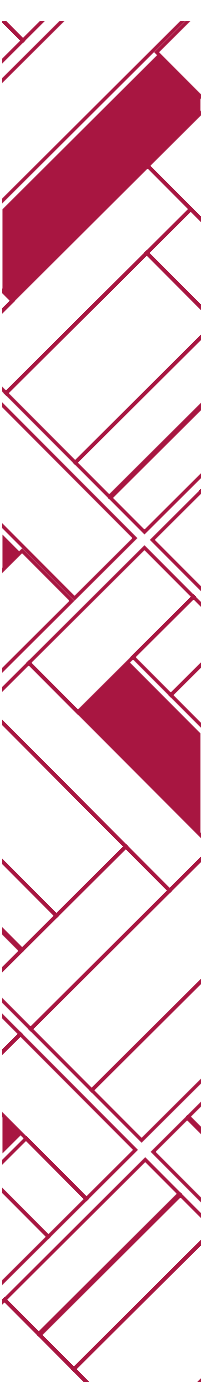

of environmental systems, such as the recovery of degraded areas and the production of food. In this sense, the objective of this project was to restore an unproductive area with the implementation of an agroforestry system in a family farm in the municipality of Ceres, GO. The methodology used was the implementation of an SAF in loco, with the direct participation of the farmer and students of the IF Goiano - Campus Ceres. In the system, vegetables and annual crops, fruit trees and tree plants were introduced. After one year of implementation, SAF provided an increase in the productive potential of the São Pedro farm area. It is an option to become degraded and/or unused/ unproductive areas in an area with food production, environmental preservation and promotion of well-being for rural families. Keywords: Family farming. Agroforestry. Ecosystem. Food security.

Resumen: Los sistemas agroforestales (SAF), cuando se implementan y realizan bajo los principios de la agroecología y con el manejo 
adecuado, permiten acelerar los procesos de regeneración de los sistemas ambientales, como la recuperación de áreas degradadas y la producción de alimentos. En este sentido, el objetivo de este proyecto era restaurar un área improductiva con la implementación de un sistema agroforestal en una granja familiar en el municipio de Ceres, GO. La metodología utilizada fue la implementación de un SAF in loco, con la participación directa del agricultor y estudiantes del IF Goiano - Campus Ceres. Se introdujeron en el sistema verduras y cultivos anuales, árboles frutales y plantas arbóreas. Después de un año de implementación, SAF proporcionó un aumento en el potencial productivo del área agrícola de São Pedro. Es una opción para convertirse en áreas degradadas y/o no utilizadas/improductivas en un área con producción de alimentos, preservación ambiental y promoción del bienestar de las familias rurales.

Palabras clave: Agricultura familiar. Agroforestería. Ecosistema. Seguridad alimentaria.

Data de submissão: 04/06/2020

Data de aprovação: 28/06/2020 


\section{Introdução}

Quando uma área se apresenta de forma degradada ou improdutiva, o processo de recuperação natural fica comprometido. Pode-se ainda essa ação ir se intensificando com o tempo, logo, a intervenção com o cercamento, plantio de mudas e sementes é de suma importância afim de acelerar o processo de recuperação desse ecossistema. Tem-se então, a potencialização dos processos naturais de regeneração do ambiente.

Nesse sentido, os sistemas agroflorestais (SAFs) ou simplesmente agrofloresta, surgem como alternativa no processo de recuperação de ecossistemas degradados pela ação do homem, possibilitando a produção agrícola aliada ao desenvolvimento florestal, agregando valor à propriedade e trazendo benefícios "econômicos" e ambientais (MENDONÇA et al., 2001; SILVA et al., 2014 \& CÂNDIDO et al., 2016).

Uns dos principais beneficiados por esse tipo de sistemas são os agricultores familiares. Como pontua Castro et. al. (2012), o grupo da agricultura familiar ao trabalhar com este tipo de sistema tem como ponto positivo a autossuficiência em mudas, plantas frutíferas, medicinais e alimentícias que contribuem diretamente para consolidação de um sistema mais sustentável e saudável para a propriedade.

Os SAF`s são um sistema que busca a sucessão natural, ou seja, com o passar do tempo as plantas de ciclo mais longo vão sucedendo outras de ciclo mais curto. Dessa forma, o produtor cultiva no mesmo espaço, culturas de interesse econômico e plantas que na sucessão formarão a nova vegetação do meio degradado. Assim, para a agricultura familiar o SAF mostra-se uma alternativa viável e de cunho agroecológico sustentável para a recomposição de reserva legal e na produção de alimentos (CÂNDIDO et al., 2016; CORDEIRO et al., 2018). 
Na recuperação de áreas degradadas ou improdutivas, uns dos dilemas é o cuidado e a manutenção das plantas, que muitas vezes morrem por falta de manejo, são atacadas por insetos, doenças e/ou suprimidas por plantas daninhas que crescem de forma espontânea nestes ambientes. Dessa forma, quando cultivada no mesmo local, plantas nativas e plantas de maior interesse ao proprietário no sistema de recuperação de áreas degradadas, estas têm maior chance de sobrevivência, pois, o produtor é mais presente na área para fazer o manejo.

As pessoas têm se conscientizado cada vez mais para a necessidade de conservação dos recursos naturais, com isso projetos de pesquisa científica e de restauração tem tido um grande avanço (MARTINS, 2007). Contudo, ainda são necessárias mais informações e ações que fomentem essa prática de preservação e restauração de áreas ambientais.

Os sistemas agroflorestais quando implantados e conduzidos sob os princípios da agroecologia, atuam na recuperação de áreas degradadas com melhorias das condições do solo e pelo manejo de seus componentes na restauração ecológica, além de produzirem alimentos (MENDONÇA et al., 2001; CÂNDIDO et al., 2016).

A restauração ecológica tem por finalidade restaurar a integridade ecológica do ecossistema, sua capacidade de resiliência, sua biodiversidade e estabilidade a longo prazo, enfatizando e promovendo a capacidade natural de mudança do ecossistema ao longo do tempo (ENGEL \& PARROTTA, 2003).

Na perspectiva agroecológica, os SAFs se mostram como uma prática que pressupõe a potencialização da regeneração natural, produção de alimento e de mudança atitudinais acerca da forma que produtores veem a produção agrícola e preservação ambiental (FÁVERO et al., 2008), uma vez que, a diversidade dos ecossiste- 
mas agroflorestais contribui para acelerar a recuperação pela função que cada espécie exerce no sistema (KAGEYAMA et al, 2003).

Objetivou-se com este projeto recuperar uma área degradada com a implantação de um sistema agroflorestal em uma propriedade de agricultura familiar no município de Ceres, GO, e, incentivar o desenvolvimento rural, fomentar a produção de alimento e usar o sistema como referência para manejo de recuperação de outras áreas na região.

\section{Metodologia}

$O$ trabalho é resultado de um projeto de extensão submetido e aprovado pelo Edital $n^{\circ} 3$, de 23 de novembro de 2018, de apoio a projetos de extensão do IF Goiano. O projeto foi implantado em março de 2019. O local de implantação do sistema agroflorestal (SAF) foi na Chácara São Pedro, de um agricultor familiar e localizada a $6 \mathrm{~km}$ da sede do município de Ceres, Goiás. A área total é de 1.100 m2; a área do projeto foi de $800 \mathrm{~m}^{2}$ e 300 m2 já estavam ocupados com vegetação arbórea oriundas de reflorestamento. A área está situada às margens do Córrego São Pedro, que pertence à bacia hidrográfica do Rio das Almas (BARBALHO et al., 2018).

Para a implantação do projeto, inicialmente, a equipe executora foi procurada pelo proprietário da chácara que se interessou em realizar um reflorestamento em sua propriedade, pois, o mesmo teve conhecimento de trabalhos nessa área e que são realizados pelo Instituto Federal Goiano - Campus Ceres. Depois, a equipe fez uma visita à propriedade afim de averiguar a possibilidade de recuperação. A área não possuía a mata ciliar e o córrego São Pedro se encontrava assoreado, com muitas propriedades à sua margem com situação de degradação. Salienta-se que os chacarei- 
ros dessa região foram notificados pelo Órgão Ambiental Municipal de Ceres para a realização da recomposição de áreas degradadas nas propriedades.

A equipe apresentou ao produtor um modelo de SAF com plantio de frutíferas e de olerícolas como uma opção mais indicada. Foi formalizada entre a equipe e o produtor as atividades que seriam implantadas, assim, foi submetido o projeto ao Edital da Instituição.

Na propriedade São Pedro a área de vegetação natural próxima ao córrego foi limpa até o curso d'água, necessitando de recuperação da vegetação. $\mathrm{Na}$ área havia apenas resíduos vegetais e algumas plantas de quiabo de plantio anterior (Figura 1).

O sistema agroflorestal implantado seguiu o modelo multiestrata (SHTORACHE, 2013), composto por espécies de interesse agrícola, como plantas frutíferas e olerícolas, cultivadas concomitantemente a espécies florestais de usos múltiplos, incluindo nativas e exóticas. Salienta-se a importância de inserir espécies de ciclo curto, como no caso de olerícolas e cultura anual, visa obter produtos nos primeiros meses de desenvolvimento do sistema, como também produção a médio e longo prazo (TEZZA, 2012).

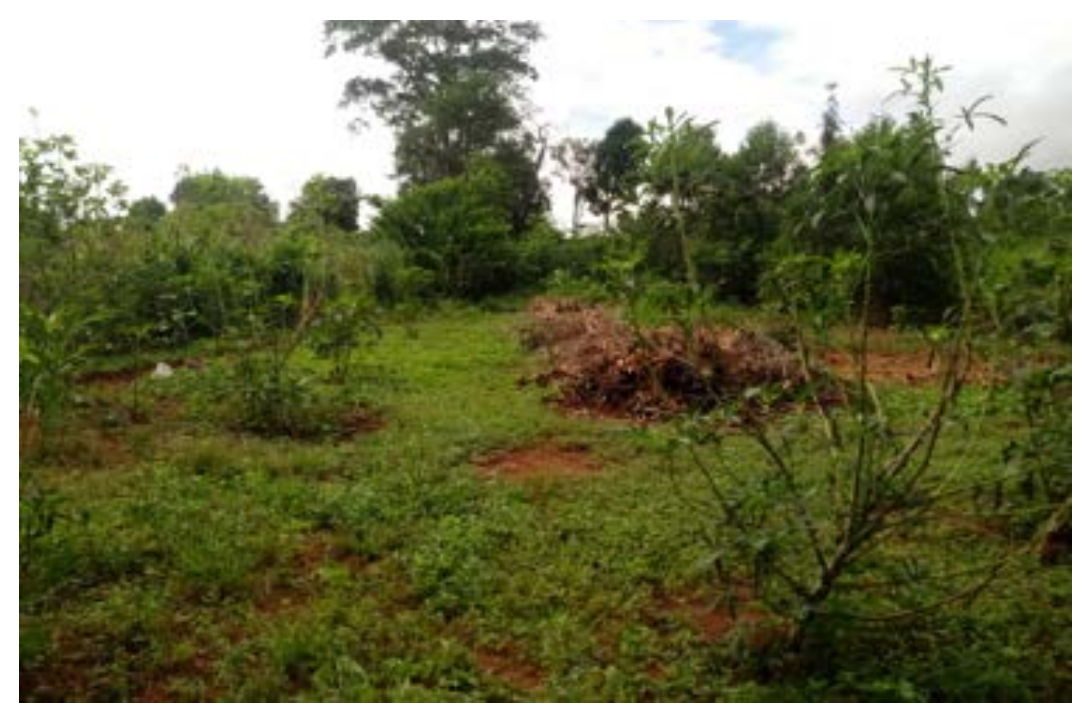

Figura 1. Situação inicial da área para a implantação do sistema agroflorestal. Fonte: Wanderson M. dos Santos (2019). 
Sistema Agroflorestal na Agricultura Familiar

Wanderson Moreira dos Santos • Layanny Robert Faria, et al...

O manejo no SAF foi o agroecológico, utilizando-se de mão-de-obra familiar, com ciclagem de nutrientes, adubação com resíduos da propriedade e esterco. O esterco utilizado (bovino) foi doado pelo IF Goiano - Campus Ceres. As espécies escolhidas para compor o sistema estão na Tabela 1.

Tabela 1. Espécies selecionadas para a implantação no SAF.

\begin{tabular}{|c|c|c|}
\hline Categoria & Nome Popular & $\begin{array}{l}\text { Quantidade } \\
\text { (Plantas) }\end{array}$ \\
\hline \multirow{9}{*}{$\begin{array}{l}\text { Cultura anual e Olerí- } \\
\text { colas }\end{array}$} & Mandioca & 99 \\
\hline & Quiabo & 40 \\
\hline & Batata doce & 100 \\
\hline & Tomate & 10 \\
\hline & Milho & 54 \\
\hline & Taro & 15 \\
\hline & Taioba & 5 \\
\hline & Inhame & 5 \\
\hline & Capim cidreira & 5 \\
\hline \multirow[t]{7}{*}{ Frutíferas } & Banana & 20 \\
\hline & Acerola & 3 \\
\hline & Manga & 3 \\
\hline & Jaca & 1 \\
\hline & Canistel & 2 \\
\hline & Mamão & 7 \\
\hline & Graviola & 1 \\
\hline \multirow[t]{6}{*}{ Arbóreas } & Coité & 3 \\
\hline & Gliricídia & 10 \\
\hline & Manguba & 1 \\
\hline & Abricó de macaco & 4 \\
\hline & & \\
\hline & $\begin{array}{l}\text { Sementes variadas de arbóre- } \\
\text { as (ipê, seringueira, sabone- } \\
\text { teira) }\end{array}$ & $0,5 \mathrm{~kg}$ \\
\hline \multirow[t]{3}{*}{ Adubo verdes } & Mucuna (Sementes) & $0,50 \mathrm{~kg}$ \\
\hline & Feijão de porco (Sementes) & $0,5 \mathrm{~kg}$ \\
\hline & Feijão guandu (Sementes) & $20 \mathrm{~g}$ \\
\hline
\end{tabular}

Fonte: Elaborados pelos autores 
As sementes para composição das espécies do SAF (Tabela 1) foram adquiridas de áreas de vegetação da região e as mudas de plantas arbóreas foram oriundas do viveiro de produção mudas do IF Goiano - Campus Ceres, e algumas produzidas pelo próprio proprietário. As mudas de plantas frutíferas foram adquiridas pelo agricultor em viveiros da cidade de Ceres.

Na área de implantação do SAF foi feita a limpeza, organizou-se os restos de resíduo vegetal e prosseguiu-se com a abertura de covas. O plantio das espécies no SAF e a semeadura foram feitas em covas escavadas manualmente. A adubação foi de acordo com a recomendação para a agricultura orgânica, fazendo uso principalmente de esterco curtido (WEINÄRTNER et al., 2006). Em todo o processo o produtor estava diretamente contribuindo em cada etapa.

A distribuição espacial das espécies foi feita de maneira uniforme, com espaçamentos definidos para cada espécie e de acordo com as características de desenvolvimento das plantas ao longo do tempo. As plantas frutíferas e arbóreas foram implantadas com quatro metros entre linhas e covas. As plantas arbóreas de grande porte foram plantadas com oito metros entre plantas e intercaladas com plantas frutíferas com espaçamento de dois metros. As plantas de adubação verde foram cultivadas adensadas afim de realizar as podas e produzir cobertura para o solo com seu material vegetal.

A área das entre linhas foi dividida em quadrantes afim de manter um espaço em produção com cultura anual e outra com adubos verdes: Feijão de porco (Canavalia ensiformis), Feijão guandu (Cajanus cajan) e Mucuna preta (Mucuna pruriens).

No plantio das frutíferas e arbóreas foram utilizadas covas com dimensões de 0,40 ×0,40 × 0,40 m. A adubação com esterco bovino foi de $5 \mathrm{~L}$ por cova e de $300 \mathrm{~g}$ por cova de calcário. Ao lado de cinco plantas de banana foi plantada uma muda de taioba (Xanthosoma sagittifolium), de inhame (Colocasia esculenta) e de Capim cidreira 
Com sete meses após implantação do SAF notou-se uma mudança na paisagem, com a presença marcante das bananeiras e da batata doce (antes na área possuía apenas plantas espontâneas). O cultivo de culturas anuais e de olerícolas, que são mais precoces, servem de estímulo ao produtor, assim, tem-se maior atenção à manutenção e recuperação da área.

A mandioca (Figura 3A) e a batata doce (Figura 3B) apresentaram-se bem desenvolvidas. Pode-se observar algumas plantas arbóreas e frutíferas próximas a essas duas culturas e que se desenvolvem muito bem no sistema.

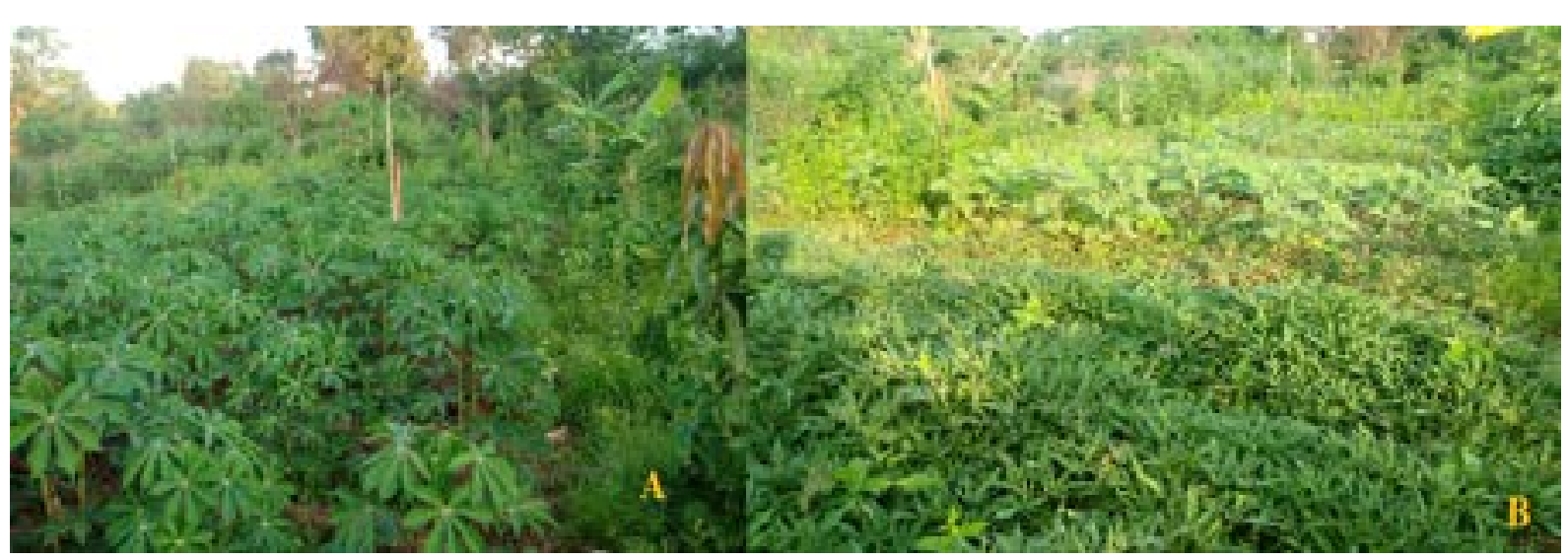

Figura 3. A - Cultivo de mandioca na entre linha do SAF; B - Cultivo de batata doce roxa e branca nas entre linhas do SAF.

Fonte: Wanderson M. dos Santos (2019).

Ressalta-se Moraes et al. (2016) que a fase inicial de uma área em que se trabalha o processo de recuperação é um dos maiores entraves, visto a necessidade de manter as plantas protegidas devido sua lentidão no seu desenvolvimento. Neste sentido, o SAF se mostrou como um estímulo para o agricultor cuidar bem das plantas e da área. Foi observado no processo de manejo do sistema maior atenção e cuidado por parte do agricultor com as plantas nativas, visto que estas, estão próximas a de outras de interesse econômico, como a bananeira, mamão e acerola. O agricultor almeja uma produção para o seu consumo durante o processo de 
recuperação do SAF e provavelmente, comercializar o excedente na vizinhança ou até mesmo na feira da agricultura familiar em Ceres. Tem-se então uma grande importância no sistema da inserção de culturas que produzirão em curto e médio prazos.

As plantas arbóreas apresentam um crescimento mais lento, assim, o cultivo de plantas de crescimento mais rápido, como os adubos verdes implantados, é uma opção para cobrir o solo rapidamente e suprimir as plantas espontâneas. Os adubos verdes têm também a função de aumentar o teor de matéria orgânica no solo, incrementar nitrogênio e suprimir o crescimento de plantas daninhas (Figura 4). O agricultor terá num período de médio e longo prazo maior fertilidade e infiltração de água no solo, menor assoreamento do córrego São Pedro e maior possibilidade de aumento da produção.

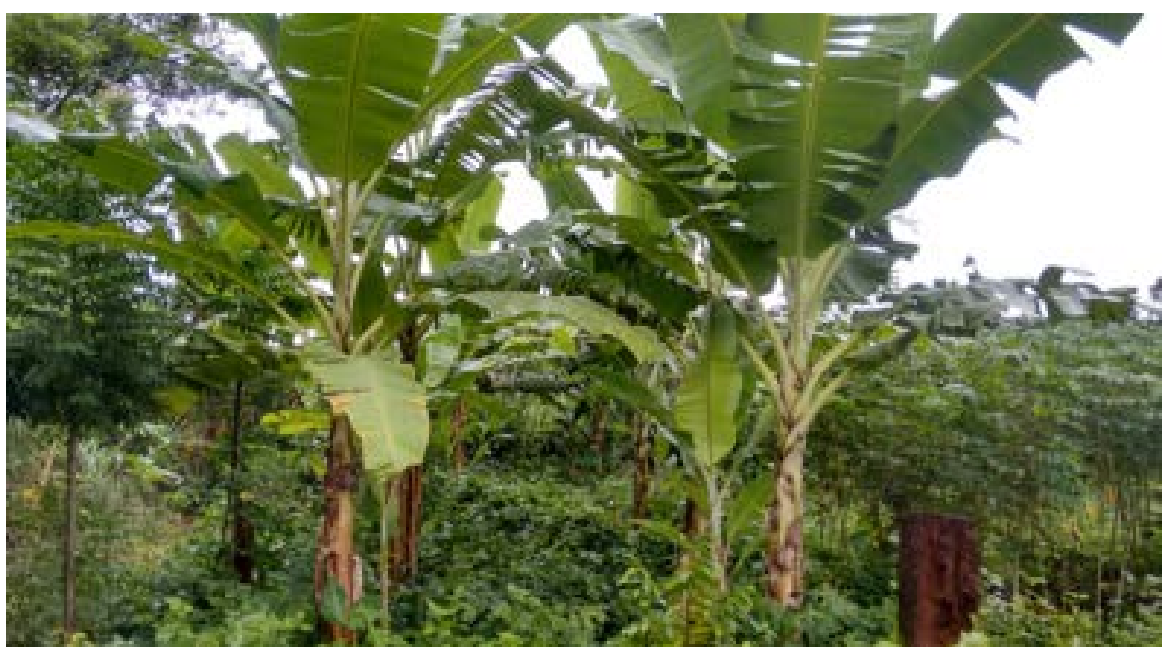

Figura 4. Adubo verde entre as plantas de banana para cobertura do solo no SAF. Fonte: Cássio S. Kran (2020).

Santos et al. (2017), destacam que os adubos verdes podem ter a capacidade de fornecer todas as quantidades de nitrogênio necessária para o bom desenvolvimento de uma cultura, sendo importante o uso deste tipo de prática em produções de cunho mais sustentáveis. 
$\mathrm{Na}$ figura 5 observa-se o sistema agroflorestal com um ano de implantação, com destaque o desenvolvimento das plantas de bananas. As bananeiras neste tipo de sistema têm função direta na produção de alimento e indireta produz biomassa. Essa biomassa fornece no sistema material orgânico com os resíduos das folhas e de pseudocaule após a retirada dos cachos (ALVES et al., 2015).

Nota-se que a organização do espaço produtivo permite uma maior diversidade de produtos em uma mesma área, obtendo diferentes colheitas ao longo do tempo, desde culturas de ciclo mais curtos (batata doce, milho, abóbora) a ciclo médio (banana, mandioca, acerola, mamão) e longo (manga, citrus e canistel). Assim, como afirma Nunes e Silva (2016), as experiências de implantação de SAFs vêm como uma forma de superar os novos desafios da produção de alimentos e restauração ambiental, em particular na mudança do sistema convencional produtivo. Cândido et al. (2016) enfatizam que os SAFs otimizam a terra, traz benefícios ambientais e econômicos para o produtor, permitindo não só uma visão de relação de proteção ambiental, mas também uma produção alicerçada na conservação.

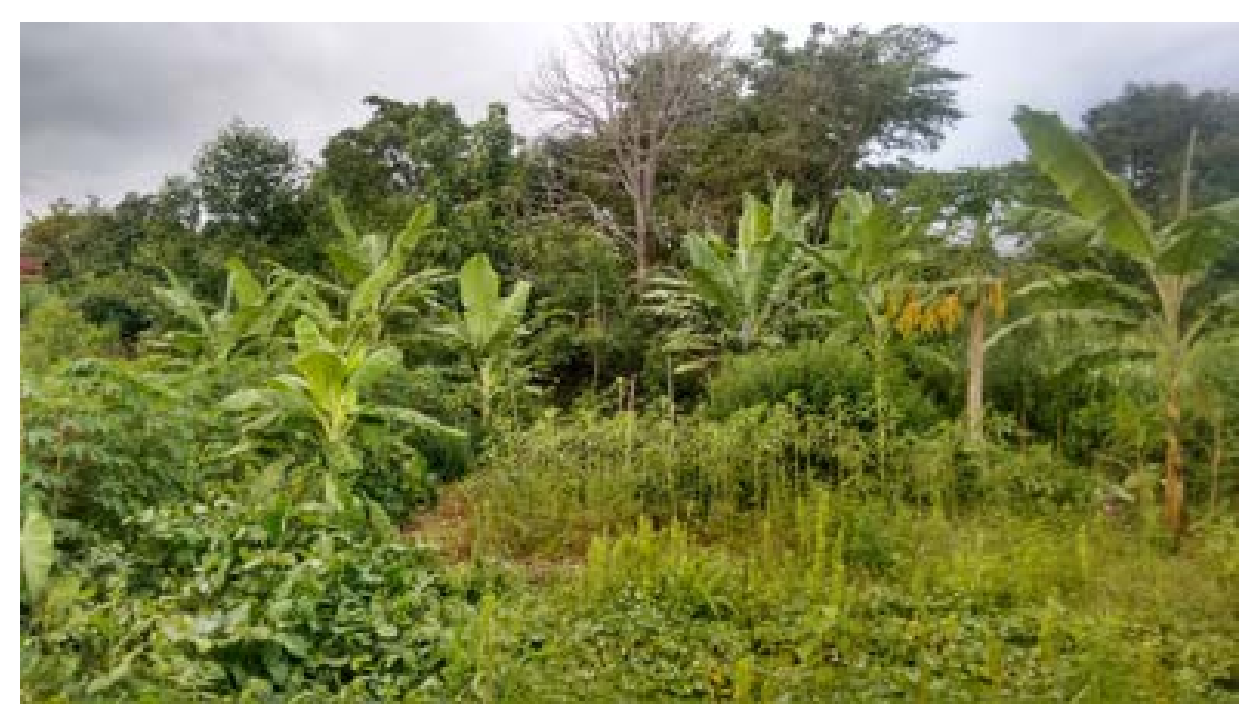

Figura 5. Sistema agroflorestal após um ano de implantação.. Fonte: Cássio S. Kran (2020). 
Neste sentido, a produção de diferentes espécies em uma mesma área tange uma proposta de quebra de paradigma cultural, visto que as experiências de reflorestamento são pautadas em suma maioria apenas no plantio de plantas nativas, geralmente sem que estas produzam alimentos para o agricultor. Portanto, esse sistema se mostrou como um potencial de novas possibilidades, sendo uma mudança gradativa, mas com o viés de sustentabilidade e a produção agrícola.

Complementa-se ainda que este projeto além de atuar na recuperação de uma área degradada, que estava sem produção, buscou informar e contribuir para a maior participação da comunidade na recuperação de outras propriedades da região que estão em situação similar. Assim, foi destacado pelo proprietário Sr. Valdir que chacareiros vizinhos o procuram para saber e conhecer melhor o sistema implantado. O próprio agricultor resolveu expandir o SAF para uma nova área de sua propriedade, um pasto marginal ao córrego São Pedro (Figura 6). As mudas plantadas na nova área foram adquiridas com produção própria e também com uma parceria com o viveiro de plantas nativas do IBAMA (Instituto Brasileiro do Meio Ambiente e dos Recursos Naturais), da cidade de Ceres.

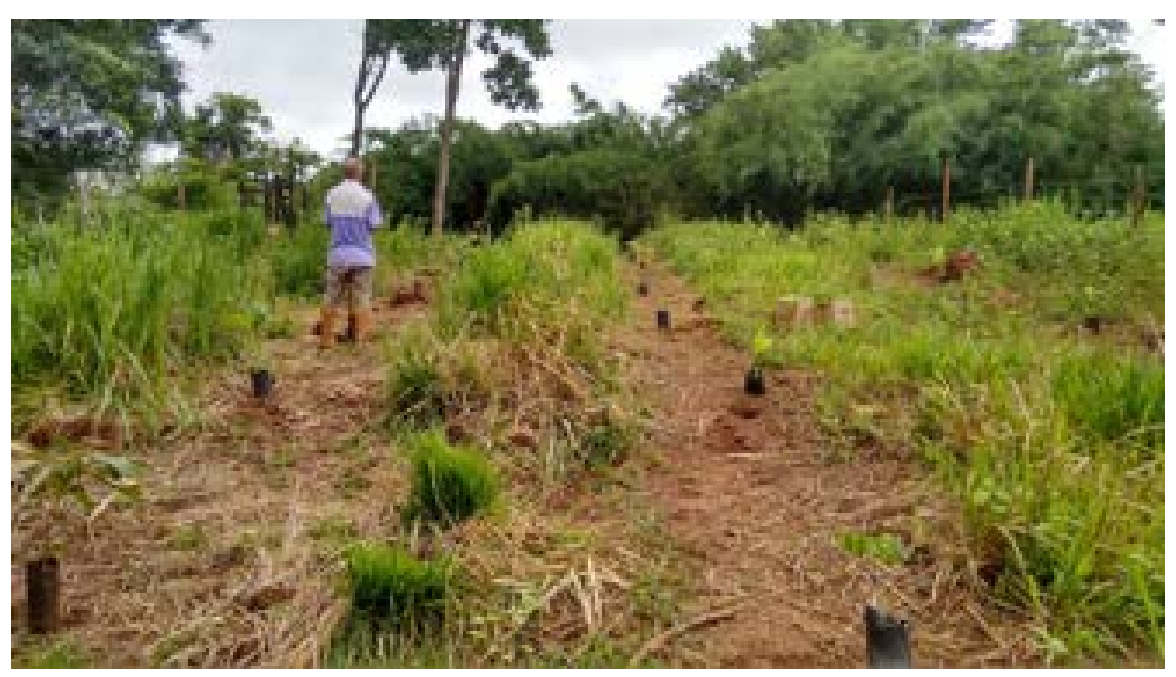

Figura 5. Sistema agroflorestal após um ano de implantação.. Fonte: Cássio S. Kran (2020). 
Nota-se que a utilização do SAF como uma estratégia de recuperação de áreas degradadas fomenta diretamente práticas conservadoras dos ecossistemas. Possibilita ao agricultor, além de executar uma atividade produtiva, contribuir para regenerar áreas degradadas.

Destaca-se a importância da implantação do projeto com a colaboração direta das atividades feitas pelo agricultor e sua família com a orientação da equipe do IF. O manejo do SAF foi repassado com instruções práticas pela equipe com visitas em momentos específicos de atividade para cada espécie, como podas de condução de plantas, adubação orgânica de cobertura, controle de plantas daninhas e irrigação no período da seca.

Parte do resultado obtido na propriedade foi apresentado no evento INTEGRA IF do IF Goiano - Campus Ceres, em Outubro de 2019, na forma de pôster.

Por fim, destaca-se que são necessárias novas práticas, estudos e aplicações do uso dos sistemas agroflorestais para fins de restauração ambiental, principalmente no seu efeito a longo prazo, seja do estudo dos componentes e seu efeito na fauna e flora do local, como nas mudanças no componente humano inserido no processo de desenvolvimento do sistema. Todavia, nota-se pela presente experiência que o uso dos SAFs pode ser um estímulo importante para os agricultores terem mais autonomia nos processos de restauração de suas áreas improdutivas ou degradadas, contribuindo para a quebra de paradigma da produção de alimentos alicerçada à preservação ambiental.

\section{Considerações Finais}

O SAF proporcionou incremento no potencial produtivo da área da chácara São Pedro. É uma opção para tornar-se áreas de- 
gradadas e/ou não utilizadas/improdutivas em uma área com produção de alimentos, preservação ambiental e promoção do bem estar para as famílias do campo.

O cultivo de plantas alimentícias junto às arbóreas para recuperar áreas degradadas ou improdutivas se mostra viável, fomentando o agricultor a ter maior cuidado com as plantas que estão em início de desenvolvimento no processo de recuperação e formação do SAF.

Este projeto de extensão é importante para a integração dos alunos do IF Goiano - Campus Ceres com os agricultores da região, pois, transfere conhecimentos e tem-se uma boa relação com as pessoas e o ambiente.

\section{6}

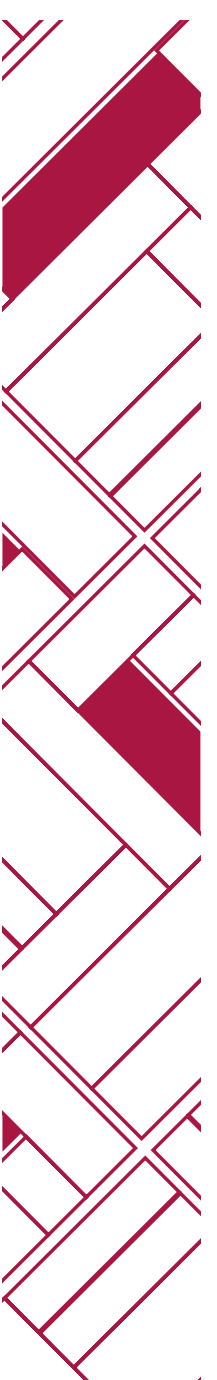

\section{Referências bibliográficas} EM: 25 JUN 2020.

ALVES, F. V.; LAURA, V. A.; ALMEIDA, R. G. Sistemas agroflorestais: a AgRopeCuÁRIA SUSTENTÁVEL. Brasília: EMBRAPA, 2015. 208 P. DisPONÍVEL EM: < HTTPS://AINFO.CNPTIA.EMBRAPA.BR/DIGITAL/BITSTREAM/ITEM/120048/1/SISTEmas-Agroflorestals-LiVRo-em-BAIXA.PdF >. Acesso em: 05 mal 2020.

BARBALHO, M. G. S.; LEAL, A. C.; NUNES, J. O. R.; MORAES, C. G.; PEIXOTO, J. C. UnidAdes da PAISAGEM dA baCIA do RIO dAs Almas, micRORregião de Ceres/GO. Planeta Amazônia - Revista Internacional de Direito Ambiental e Políticas Públicas, n. 10, p. 153-166, 2018. Disponível em <HTTPS://PERIODICOS.UNIFAP.BR/INDEX.PHP/PLANETA/ARTICLE/VIEW/5210>. ACESSO

CÂNDIDO, V. A.; PINTO, L. V. A.; BOGARIM P. C.; ROSA, S. D.; SILVA, R. M.; BARBOSA, J. M. N. Sistema AgROfLORESTAL PARA RECOMPOSIçÃo DE Reserva legal em propriedades de agricultores familiares. Revista Agrogeo- 
AMBientAL, V. 8, N. 2, 2016. DisponíVEL EM <DX.DOI.ORG/10.18406/23161817v8N22016821>. ACESSO EM: 25 JUN 2020.

CAstro, D.; MEllo, R. S. P.; POESTeR, G. C. (Orgs). Práticas para restauração da mata ciliar. Porto Alegre: Catarse - Coletivo de ComuniCAÇÃO, 2012. 60 P.; IL. ISBN 85-63-199072.

CORDEIRO, S. A.; SILVA, M. L.; OLIVEIRA NETO, S.; OLIVEIRA, T. M. SIMULAÇÃO DA VARIAÇÃO DO ESPAÇAMENTO NA VIABILIDADE ECONÔMICA de um Sistema agroflorestal. Floresta Ambiental, v. 25, n. 1, 2018. DISPONÍVEL EM < HTTPS://WWW.SCIELO.BR/SCIELO.PHP?SCRIPT=SCI_ARTTEXT\&PID=S2179-80872018000100104\&LNG=PT\&TLNG=PT>. ACESSO EM: 25 JUN 2020.

ENGEL, V. L.; PARROTTA, J. A. Definindo A RESTAURAÇÃo ECOLÓGICA: tendÊNCIAS E PERSPECTIVAS MUNDIAIS. IN: KAGEYAMA, P. Y; OLIVEIRA, R. E.; MORAES, L. F. D.; ENGEL, V. L.; GANDARA, F. B. (CoOrd.). Restauração Ecológica de Ecossistemas Naturais. Botucatu: FePAF, 2003, p. 1-26. FÁVERO. C.; LOVO, I. V.; MENDOÇA, E. S. ReCUPERAÇÃo de ÁREA deGRAdada com sistema agroflorestal no Vale do Rio Doce, Minas Gerais. 2008. R. Árvore, ViçOSA-MG, v. 32, N. 5, P. 861-868, 2008. Disponível eM <HTTP://DX.DOI.ORG/10.1590/S0100-67622008000500011>. ACESSO EM: 20 JUN 2020.

KAGEYAMA, P. Y.; OLIVEIRA, R. E.; MORAES, L. F. D.; ENGEL, V. L.; GANDARA, F. B. Restauração ecológica de ecossistemas naturais. Fundação de Estudos e Pesquisas Agrícolas e Florestais - FepaF, Botucatu - SP, $1^{\circ}$ ED., 2003, 340 P.

Martins, S. V. Recuperação de Matas Ciliares. Aprenda Fácil Editora. VIÇOSA, MG. $2^{\circ}$ EDIÇÃO, 2007. 
MENDONÇA, E. S.; LEITE, L. F. C.; FERREIRA NETO, P. S. F. CULTIVO DO CAFÉ EM SISTEMA AGROFLORESTAL: UMA OPÇÃO PARA RECUPERAÇÃO DE solos degradados. Revista Árvore, v. 25, n. 3, p. 375-383, 2001. DISPONIVEL EM: < HTTPS://WWW.SCIELO.BR/SCIELO.PHP?SCRIPT=SCI_ARTTEXT\&PID=S0100-67622008000500011\&LNG=PT\&TLNG=PT>. ACESSO EM: 25 JUN 2020.

MORAES, L. F. D.; ASSUMPÇÃO, J. M.; PEREIRA, T. S. LUCHIARI, C. Manual Técnico para a Restauração de Áreas Degradadas no Estado do Rio de Janeiro. Rio de Janeiro: Jardim Botânico, 2013. 84 P. Disponível em: <HTTP://WWW.JBRJ.GOV.BR/SITES/ALL/THEMES/CORPORATECLEAN/CONTENT/PUBLICACOES/MANUAL_TECNICO_RESTAURACAO.PDF >. ACESSO EM 05 MAI 2020.

NUNES, P. J.; SILVA, T. B. IMPLANTAÇÃO DE SISTEMAS AGROFLORESTAIS: A eXPeriênCia do assentamento Mário Lago, Ribeirão Preto, estado de São Paulo. Informações Econômicas, SP, v. 46, N. 3, 2016. Disponível EM: < HTTP://WWW.IEA.SP.GOV.BR/FTPIEA/PUBLICACOES/IE/2016/TEC4-0616.PDF>. ACESSO EM 10 MAI 2020.

SANTOS, T. L.; NUNES, A. B. A.; GIONGO, V.; BARROS, V. S.; FIGUEIRÊDO, M. C. B. Cleaner fruit PRODUCtion With GREEN MANURE: the CASE of brazilian melons. Journal of Cleaner Production, v. 181, p. 260-270, 2017. DisPONÍVEL EM: < HTTPS://WWW.SCIENCEDIRECT.COM/SCIENCE/ARTICLE/ABS/ PII/S0959652617332602>. ACESSO EM 10 MAI 2020.

ShtORACHE, G. F. Atributos físicos do solo em sistema agroflorestal Multiestrata Sucessional. Dissertação (Pós-Graduação em Ciência do Solo). CuRItiBa, 2013. Disponível EM: <HTtP://WWW.PGCISOLO.AGRARIAS.UFPR. BR/PORTAL/WP-CONTENT/UPLOADS/2013/04/2013_05_13_SHTORACHE.PDF>. ACESSO EM 17 feV 2019. 
SILVA, T. T.; DRUMOND, M. A.; BAKKE, I. A. Sistema Agroflorestal em Nova Olinda, Ceará: Uma experiência de sucesso. Revista Verde de Agroecologia e Desenvolvimento Sustentável. v. 9, N. 3, 2014. DisPONÍVEL EM: < HTTPS://WWW.GVAA.COM.BR/REVISTA/INDEX.PHP/RVADS/ARTICLE/ VIEW/2803/2390>. ACESSO: 14 fEV 2019.

TeZZA, B. Recuperação de Mata Ciliar com Sistema Agroflorestal em Pequena propriedade RURal, Município de Urussanga/SC. Monografia (Pós-graduação em Ecologia e Manejo de Recursos Naturais). Universidade do Extremo Sul Catarinense - UNESC, 2012, 78 p. Disponível em: < HTTP://REPOSITORIO.UnESC.NET/HANDLE/1/1166>. ACESSO EM 15 FEV 2019. Weinärtner, M. A.; AldRighi, C. F. S.; Medeiros, C. A. B. Práticas agroecológicas: adubação orgânica, Pelotas, RS: Embrapa Clima TemperADO, $1^{\circ}$ ED., 2006. DISPONÍVEL EM: <HTTPS://WWW. INFOTECA.CNPTIA.EMBRAPA. BR/BITSTREAM/DOC/903698/1/AdUBACAOORGANICA.PDF>. ACESSO EM: 10 MAR 2019. 